\title{
TRATAMENTOS PARA A SUPERAÇÃO DE DORMÊNCIA EM SEMENTES DE Brachiaria humidicola (Rendle) Schweick ${ }^{1}$
}

\author{
Caroline Jácome Costa 2 , Raphael Branco de Araújo ${ }^{3}$, Hugo Dias da Costa Villas Bôas ${ }^{4}$
}

\section{ABSTRACT \\ TREATMENTS FOR SEED DORMANCY \\ RELEASE IN Brachiaria humidicola (Rendle) Schweick}

Most of the tropical forages is affected by seed dormancy, which can hinder the determination of its physiological quality, field seedling emergence, and the establishment of pastures. This study aimed to evaluate the effectiveness of acid scarification and application of germination promoters on the dormancy release of stored seeds of Brachiaria humidicola. Seeds stored during nine and 21 months were scarified with the aid of concentrated sulfuric acid. Afterwards, the seeds were placed to germinate on a blotter paper moistened with the following solutions: $\mathrm{KNO}_{3}(0.2 \%)$, gibberellic acid $\left(100 \mathrm{mg} \mathrm{L}^{-1}\right), \mathrm{H}_{2} \mathrm{O}_{2}(0.30 \%)$, and distilled water. The seeds remained for 21 days under an alternating temperatures regime $\left(15-35^{\circ} \mathrm{C}\right)$ and light cycles $(8$ hours of light $/ 16$ hours of darkness), when the percentages of germination and dormant seeds were evaluated. Acid scarification was more effective on dormancy release in the seeds stored up to nine months, in comparison to the ones stored for 21 months, with reduction of dormant seeds percentage from $84 \%$ to $36 \%$. Acid scarification of seeds stored up to nine months, followed by the gibberellic acid treatment, or the storage of seeds up to 21 months resulted in a $60 \%$ germination rate. The storage of $B$. humidicola seeds up to 21 months is more effective for dormancy release than the acid scarification or the application of germination promoters.

KEY-WORDS: Creeping signal grass; acid scarification; storage.

\section{INTRODUÇÃO}

O Brasil é o maior produtor, consumidor e exportador de sementes de espécies forrageiras tropicais, com produção estimada de 70 mil toneladas, na safra 2008/2009 (Abrasem 2010), já tendo alcançado produções superiores a 100 mil toneladas, em safras anteriores. Mais de $80 \%$ do mercado é dominado por cultivares do gênero Brachiaria, cuja introdução

\section{RESUMO}

A maioria das gramíneas forrageiras tropicais é afetada pela dormência das sementes, a qual pode dificultar a determinação da sua qualidade fisiológica, emergência das plântulas no campo e o estabelecimento das pastagens. Objetivouse, no presente trabalho, verificar a eficácia da escarificação ácida e da aplicação de substâncias promotoras à germinação na superação da dormência de sementes armazenadas de Brachiaria humidicola. Sementes armazenadas por nove e 21 meses foram escarificadas, empregando-se ácido sulfúrico concentrado, e colocadas para germinar em substrato umedecido com as seguintes soluções: nitrato de potássio $(0,2 \%)$, ácido giberélico (100 $\left.\mathrm{m} \mathrm{L} \mathrm{L}^{-1}\right)$, peróxido de hidrogênio $(0,30 \%)$ e água destilada. As sementes permaneceram por 21 dias sob temperaturas alternadas de $15-35^{\circ} \mathrm{C}$ e fotoperíodo de 8 horas, sendo avaliadas quanto à percentagem de plântulas normais e de sementes dormentes. Nas sementes armazenadas por nove meses, a escarificação ácida foi mais efetiva do que nas sementes armazenadas por 21 meses, ocorrendo redução da percentagem de sementes dormentes de $84 \%$ para $36 \%$. A escarificação ácida das sementes armazenadas por nove meses, seguida do tratamento com ácido giberélico, ou o armazenamento das sementes por 21 meses resultou na obtenção de $60 \%$ de plântulas normais. O armazenamento das sementes de $B$. humidicola por 21 meses é mais efetivo para a superação da dormência do que a escarificação ácida ou a aplicação de substâncias promotoras à germinação.

PALAVRAS-CHAVE: Quicuio-da-Amazônia; escarificação ácida; armazenamento.

na formação de pastagens, no Cerrado, resultou em ganhos significativos nos índices de produtividade de carne, devido ao rápido aumento da capacidade de suporte das pastagens. Isto ocorreu devido à ampla adaptação das espécies às condições edafoclimáticas da região, sobretudo aos solos ácidos e de baixa fertilidade predominantes nos trópicos (Rao et al. 1996). Brachiaria humidicola (Rendle) Schweick apresenta maior tolerância a solos pouco drenados,

1. Trabalho recebido em jul./2011 e aceito para publicação em nov./2011 (nº registro: PAT 15100/ DOI: 10.5216/pat.v41i4.15100).

2. Embrapa Clima Temperado, Pelotas, RS, Brasil.E-mail: caroline.costa@cpact.embrapa.br.

3. Nufarm Indústria Química e Farmacêutica, Gurupi, TO, Brasil. E-mail: rbaraujo.agro@yahoo.com.br.

4. Embrapa Transferência de Tecnologia, Brasília, DF, Brasil.E-mail: villas@sede.embrapa.br. 
grande capacidade de estabelecimento em novas áreas e resistência à elevada pressão de pastejo, apesar de menor qualidade nutricional, quando comparada a outras espécies do gênero, como $B$. decumbens, $B$. brizantha ou $B$. ruziziensis (Lapointe \& Miles 1992, Dias-Filho \& Carvalho 2000, Cook et al. 2005). A propagação da espécie pode ocorrer vegetativamente ou, no caso de grandes áreas, por meio de sementes.

A maioria das gramíneas forrageiras tropicais é afetada pela dormência das sementes, a qual pode dificultar a determinação da sua qualidade fisiológica e a emergência das plântulas no campo e o estabelecimento de pastagens. No caso de sementes de $B$. humidicola, há indicações de que sementes recém-colhidas devem permanecer armazenadas por 6 a 9 meses, ou serem escarificadas com ácido sulfúrico, antes da semeadura, como forma de reduzir a intensidade da dormência. Estudos relacionando a resposta de sementes de $B$. humidicola a diferentes tratamentos para superação da dormência, entretanto, têm apresentado resultados contraditórios e inconclusivos. Para alguns autores, a escarificação de sementes recém-colhidas auxilia na redução da intensidade de dormência (Oliveira \& Mastrocola 1983). Para outros, a escarificação ácida é prejudicial à qualidade fisiológica das sementes, não sendo recomendada (Atalla \& Tosello 1979, Rodrigues et al. 1986, Macedo et al. 1994, Usberti \& Martins 2007).

Assim, objetivou-se, no presente trabalho, verificar a eficácia da escarificação ácida e da aplicação de substâncias promotoras à germinação na superação da dormência de sementes armazenadas de Brachiaria humidicola.

\section{MATERIAL E MÉTODOS}

Os experimentos foram conduzidos no Laboratório de Análise de Sementes da Embrapa Cerrados, em Planaltina (DF), e na Unidade de Produção de Sementes da Embrapa Transferência de Tecnologia, localizada em Brasília (DF).

Foram utilizados dois lotes de sementes de Brachiaria humidicola, colhidas na inflorescência (cacho): um lote de sementes foi colhido em $2008 \mathrm{e}$ armazenado por 21 meses e o outro colhido em 2009 e armazenado por nove meses. Previamente à execução dos experimentos, determinou-se a viabilidade das sementes, pelo teste de tetrazólio. Para o teste, adotou-se a metodologia descrita por Dias \& Alves
(2000), para Brachiaria brizantha, com algumas modificações, empregando-se duas subamostras de 100 sementes de cada lote, tomadas da porção de sementes puras. As sementes foram pré-acondicionadas sobre folhas de papel umedecido com água destilada, por 16 horas, a $25^{\circ} \mathrm{C}$. Após este período, foram seccionadas longitudinalmente, dividindo-se o embrião ao meio, e imersas em solução de tetrazólio $(0,1 \%)$, a $35^{\circ} \mathrm{C}$, por 4 horas. A avaliação da viabilidade das sementes foi realizada empregando-se os critérios estabelecidos nas Regras para Análise de Sementes (Brasil 2009).

Metade das sementes de cada lote foi submetida à escarificação química, empregando-se ácido sulfúrico $\left(\mathrm{H}_{2} \mathrm{SO}_{4}\right) 98 \%$, durante 15 minutos. Após a escarificação, as sementes foram lavadas em água corrente, por 3 minutos, e secas superficialmente em ambiente de laboratório, por 24 horas, sobre folhas de papel mata-borrão. Posteriormente, as sementes, escarificadas e intactas, foram colocadas para germinar em caixas plásticas (gerbox), sobre folhas de papel mata-borrão umedecido com as seguintes soluções: nitrato de potássio $\left(\mathrm{KNO}_{3}\right)$ 0,2\%; ácido giberélico $\left(\mathrm{GA}_{3}\right) 100 \mathrm{mg} \mathrm{L}^{-1}$; peróxido de hidrogênio $\left(\mathrm{H}_{2} \mathrm{O}_{2}\right)$ $0,30 \%$; e água destilada. $\mathrm{O}$ substrato foi reumedecido com água destilada, sempre que necessário. As sementes permaneceram por 21 dias em alternância de $15-35^{\circ} \mathrm{C}$ e fotoperíodo de 8 horas (Brasil 2009), sendo avaliadas aos 7, 14 e 21 dias, quanto à percentagem de plântulas normais e de sementes dormentes.

O experimento foi conduzido em delineamento inteiramente casualizado, com quatro repetições de 100 sementes, em esquema fatorial $2 \times 2 \times 4$ (período de armazenamento $x$ escarificação $x$ tratamentos para superação da dormência das sementes). Os dados obtidos foram submetidos a análise estatística, sendo os efeitos dos fatores e suas interações analisados por meio da comparação de médias, pelo teste Tukey $(\mathrm{p}<0,05)$. Para a análise estatística, os valores observados foram transformados em arc sen $\mathrm{x}$.

\section{RESULTADOS E DISCUSSÃO}

Sementes de $B$. humidicola armazenadas por 21 e 9 meses e avaliadas pelo teste de tetrazólio apresentaram, em média, $69 \%$ e $77 \%$ de sementes viáveis, respectivamente.

Os dados médios de percentagem de sementes dormentes observadas após a escarificação, em função do período de armazenamento, estão apresentados na Tabela 1. Verificou-se que a escarificação ácida foi 
Tabela 1. Percentagem de sementes dormentes de Brachiaria humidicola, após a escarificação ácida, em função do período de armazenamento (Planaltina, DF, 2010).

\begin{tabular}{lcc}
\hline \multirow{2}{*}{ Tratamentos } & \multicolumn{2}{c}{ Período de armazenamento } \\
\cline { 2 - 3 } & 21 meses & 9 meses \\
\hline Sem escarificação & $34 \mathrm{Ab}$ & $84 \mathrm{Aa}$ \\
Com escarificação & $39 \mathrm{Aa}$ & $36 \mathrm{Ba}$ \\
\hline C.V. $(\%)$ & \multicolumn{2}{c}{14,2} \\
\hline
\end{tabular}

Médias seguidas pela mesma letra, minúscula na linha e maiúscula na coluna, não diferem entre si, pelo teste Tukey $(\mathrm{p}<0,05)$.

mais efetiva em reduzir a dormência nas sementes armazenadas por nove meses (sementes mais novas) do que nas sementes armazenadas por 21 meses, quando ocorreu redução da percentagem de sementes dormentes de $84 \%$ para $36 \%$. Nas sementes armazenadas por 21 meses, por outro lado, a escarificação ácida não teve efeito, sendo que a percentagem de sementes dormentes foi naturalmente menor e não se alterou após o tratamento.

Alguns trabalhos têm demonstrado que a dormência em sementes de gramíneas forrageiras é mais acentuada em sementes recém-colhidas, o que pode explicar o maior efeito da escarificação sobre sementes mais novas. Neste sentido, Oliveira \& Mastrocola (1983) ressaltaram que a escarificação ácida de sementes de $B$. humidicola favoreceu a germinação apenas de sementes provenientes de colheita recente, tendo observado efeito da escarificação com ácido sulfúrico apenas em sementes de $B$. humidicola colhidas há quatro meses, relativamente às sementes colhidas há dez meses, nas quais o tratamento interferiu negativamente na germinação. Da mesma forma, a escarificação de sementes de $B$. decumbens recém-colhidas foi mais eficiente do que a escarificação de sementes submetidas a dez meses de armazenamento (Grof 1968).

Praticamente, a mesma incidência de sementes dormentes foi observada em sementes colhidas em 2008 e armazenadas por 21 meses e em sementes colhidas em 2009, armazenadas por nove meses e submetidas à escarificação ácida (Tabela1). Com o auxílio destes resultados, pôde-se inferir que o armazenamento de sementes de $B$. humidicola por 21 meses e a escarificação ácida de sementes colhidas e armazenadas por nove meses apresentaram efeitos similares, quanto à redução da percentagem de sementes dormentes, no teste de germinação, contrariando resultados anteriores obtidos com a espécie, segundo os quais o armazenamento e a escarificação ácida foram prejudiciais à qualidade fisiológica das sementes e não foram efetivos em reduzir a intensidade de dormência (Atalla \& Tosello 1979, Oliveira \& Mastrocola 1983, Macedo et al. 1994, Custódio 2000, Usberti \& Martins 2007). Estes resultados contraditórios podem refletir diferenças entre os genótipos estudados, conforme já destacado por Usberti et al. (2000), ao observarem diferenças na intensidade de dormência entre híbridos de Panicum maximum, além de possíveis diferenças na idade das sementes analisadas.

Após a escarificação das sementes, os tratamentos empregados para estimular a germinação provocaram efeitos diferenciados, sendo que o ácido giberélico e o peróxido de hidrogênio produziram os melhores resultados, reduzindo a percentagem de sementes dormentes para menos de $30 \%$, independentemente da idade das sementes (Tabela 2). Todavia, observou-se que o peróxido de hidrogênio, embora tenha reduzido a percentagem de sementes dormentes e estimulado a germinação, promoveu o aumento da incidência de anormalidades nas plântulas formadas. Sem a escarificação das sementes, estes tratamentos foram menos efetivos e nenhum deles conseguiu reduzir a percentagem de sementes dormentes para menos de 50\% (Tabela 2).

É provável que a escarificação das sementes, ao degradar parcial ou totalmente os envoltórios externos (glumas e glumelas), tenha favorecido as reações de oxidação no embrião e permitido a absorção de substâncias promotoras à germinação, reduzindo a intensidade de dormência. Usberti \& Martins (2007), embora não tenham observado efeitos positivos da escarificação ácida em sementes de $B$. humidicola, ressaltaram que este tratamento pode simular a ação do fogo, empregado para renovação de pastagens, em razão do seu efeito dessecante e das

Tabela 2. Percentagem de sementes dormentes de Brachiaria humidicola, em função da escarificação ácida e soluções de embebição para superação da dormência (Planaltina, DF, 2010).

\begin{tabular}{ccc}
\hline Tratamentos & Com escarificação & Sem escarificação \\
\hline $\mathrm{KNO}_{3}$ & $55 \mathrm{Aa}$ & $52 \mathrm{Ab}$ \\
$\mathrm{AG}_{3}$ & $28 \mathrm{Bb}$ & $62 \mathrm{Aab}$ \\
$\mathrm{H}_{2} \mathrm{O}_{2}$ & $27 \mathrm{Bb}$ & $60 \mathrm{Aab}$ \\
Água destilada & $42 \mathrm{Ba}$ & $69 \mathrm{Aa}$ \\
\hline C.V. (\%) & \multicolumn{3}{c}{14,2} \\
\hline
\end{tabular}

Médias seguidas pela mesma letra, minúscula na linha e maiúscula na coluna, não diferem entre si, pelo teste Tukey $(\mathrm{p}<0,05)$. 
altas temperaturas geradas após sua aplicação nas sementes, o que favoreceria maior absorção de água e difusão de oxigênio. A escarificação ácida também foi considerada, por Almeida \& Silva (2004), como alternativa para redução da dormência de sementes de $B$. humidicola cv. Llanero.

No caso das sementes armazenadas por $21 \mathrm{me-}$ ses, o tratamento com peróxido de hidrogênio reduziu a percentagem de sementes dormentes para $26 \%$ (Tabela 3), mas a percentagem de plântulas normais foi negativamente afetada, nas sementes previamente escarificadas (Tabela 4). Da mesma forma, no caso das sementes armazenadas por nove meses, este tratamento não favoreceu a formação de plântulas normais, independentemente da escarificação das sementes (Tabela 4). Em contrapartida, o emprego de ácido giberélico em sementes armazenadas por nove meses e submetidas à escarificação ácida favoreceu a obtenção de plântulas normais, resultando em $60 \%$ de germinação (Tabela 4), corroborando os resultados obtidos por Castiblanco \& Mendoza (1985), que consideraram que o melhor tratamento para a superação

Tabela 3. Percentagem de sementes dormentes de Brachiaria humidicola, em função do período de armazenamento e de diferentes soluções de embebição, para superação da dormência (Planaltina, DF, 2010).

\begin{tabular}{ccc}
\hline \multirow{2}{*}{ Tratamentos } & \multicolumn{2}{c}{ Período de armazenamento } \\
\cline { 2 - 3 } & 21 meses & 9 meses \\
\hline $\mathrm{KNO}_{3}$ & $50 \mathrm{Aa}$ & $56 \mathrm{Ba}$ \\
$\mathrm{AG}_{3}$ & $40 \mathrm{Aba}$ & $48 \mathrm{Ba}$ \\
$\mathrm{H}_{2} \mathrm{O}_{2}$ & $26 \mathrm{Cb}$ & $61 \mathrm{Ba}$ \\
Água destilada & $31 \mathrm{BCb}$ & $78 \mathrm{Aa}$ \\
\hline $\mathrm{CV}(\%)$ & \multicolumn{3}{c}{14,2} \\
\hline
\end{tabular}

Médias seguidas pela mesma letra, minúscula na linha e maiúscula na coluna, não diferem entre si, pelo teste Tukey $(p<0,05)$. da dormência de sementes de $B$. humidicola consistiu na escarificação ácida das sementes, seguida da aplicação de 300 ppm de ácido giberélico.

Da mesma forma, Rodrigues et al. (1986) relataram que o tratamento de sementes de $B$. humidicola com ácido giberélico mostrou-se eficaz para a superação da dormência, após nove meses de armazenamento e lavagem prévia das sementes em água corrente, por 48 horas.

No presente trabalho, as sementes não submetidas à escarificação ácida apresentaram apenas $11 \%$ de germinação, após serem semeadas no substrato umedecido com a solução de ácido giberélico (Tabela 4). Substituindo-se o ácido giberélico pelo nitrato de potássio, este percentual aumentou para $27 \%$. No caso das sementes armazenadas por 21 meses, entretanto, o efeito do ácido giberélico não foi significativamente diferente do efeito da água, não sendo, portanto, recomendável a sua utilização. Outros autores já observaram respostas variáveis de substâncias promotoras à germinação, dependendo da idade das sementes. Por exemplo, Oliveira \& Mastrocola (1983) observaram que a escarificação ácida e a aplicação de nitrato de potássio apenas resultaram em efeitos positivos à germinação em sementes novas de $B$. humidicola.

O armazenamento das sementes de $B$. humidicola por 21 meses foi mais efetivo para a superação da dormência das sementes do que quaisquer dos tratamentos aplicados (escarificação ácida ou aplicação de nitrato de potássio, ácido giberélico ou peróxido de hidrogênio) (Tabela 4). O armazenamento já foi considerado, em outras espécies, como agente capaz de atenuar a dormência das sementes ou afetar a resposta das mesmas a tratamentos aplicados com esta finalidade, conforme observado em B. decumbens (Condé \& Garcia 1985a, Rivero \&

Tabela 4. Percentagem de plântulas normais de Brachiaria humidicola, em função do período de armazenamento, da escarificação ácida e de diferentes soluções de embebição, para superação da dormência (Planaltina, DF, 2010).

\begin{tabular}{|c|c|c|c|c|}
\hline \multirow{3}{*}{ Tratamentos } & \multicolumn{4}{|c|}{ Período de armazenamento } \\
\hline & \multicolumn{2}{|c|}{21 meses } & \multicolumn{2}{|c|}{9 meses } \\
\hline & Com escarificação & Sem escarificação & Com escarificação & Sem escarificação \\
\hline $\mathrm{KNO}_{3}$ & $25 \mathrm{Ab}$ & $41 \mathrm{Aa}$ & $9 \mathrm{Bc}$ & $27 \mathrm{Aa}$ \\
\hline $\mathrm{AG}_{3}$ & $50 \mathrm{Aa}$ & $50 \mathrm{Aa}$ & $60 \mathrm{Aa}$ & $11 \mathrm{Bab}$ \\
\hline $\mathrm{H}_{2} \mathrm{O}_{2}$ & $0 \mathrm{Bc}$ & $63 \mathrm{Aa}$ & $0 \mathrm{Bd}$ & $6 \mathrm{Ab}$ \\
\hline Água destilada & $55 \mathrm{Aa}$ & $60 \mathrm{Aa}$ & $31 \mathrm{Ab}$ & $2 \mathrm{Bb}$ \\
\hline $\mathrm{CV}(\%)$ & \multicolumn{4}{|c|}{23,3} \\
\hline
\end{tabular}

Médias seguidas pela mesma letra, minúscula na coluna e maiúscula na linha, dentro de cada período de armazenamento, não diferem entre si, pelo teste Tukey (p <0,05) 
Espinosa 1988, Gonzalez et al. 1993, Lima \& Cardoso 1996), B. brizantha (Previero 1996), Andropogon gayanus (Eira 1983) e Panicum maximum (Condé \& Garcia 1985b).

\section{CONCLUSÃO}

O armazenamento de sementes de $B$. humidicola por 21 meses foi mais efetivo para a superação da dormência do que a escarificação ácida ou a aplicação de substâncias promotoras à germinação.

\section{REFERÊNCIAS}

ALMEIDA, C. R.; SILVA, W. R. Comportamento da dormência em sementes de Brachiaria dictyoneura cv. Llanero submetidas às ações do calor e do ácido sulfúrico. Revista Brasileira de Sementes, Pelotas, v. 26, n. 1, p. 4449, 2004.

ASSOCIAÇÃO BRASILEIRA DE SEMENTES E MUDAS (Abrasem). Anuário Abrasem 2010. Pelotas: Becker \& Peske, 2010.

ATALLA, L. M. P.; TOSELLO, J. Observações sobre dormência em duas espécies de Brachiaria: $B$. decumbens e B. humidicola, em condições de laboratório. Científica, São Paulo, v. 7, n. 3, p. 353-355, 1979.

BRASIL. Ministério da Agricultura, Pecuária e Abastecimento. Secretaria de Defesa Agropecuária. Regras para análise de sementes. Brasília: MAPA/ACS, 2009.

CASTIBLANCO, L. A.; MENDOZA, P. Efecto de almacenamiento y tratamiento químico a las semillas sobre germinación de Brachiaria humidicola y Brachiaria dictyoneura. ICA Informa, Bogotá, v. 19, n. 3, p. 33-35, 1985.

CONDÉ, A. R.; GARCIA, J. Efeito da época de colheita sobre o potencial de armazenamento das sementes do capim-braquiária, em condições ambientais. Revista Brasileira de Sementes, Brasília, DF, v. 7, n. 2, p. 85-92, 1985a.

CONDÉ, A. R.; GARCIA, J. Efeito da maturação e do armazenamento sobre a qualidade das sementes do capimcolonião. Revista Brasileira de Sementes, Brasília, DF, v. 7, n. 3, p. 115-122, 1985b.

COOK, B. G. et al. Tropical forages: an interactive selection tool. Brisbane: CSIRO/DPI\&F(Qld)/CIAT/ILRI, 2005. 1 CD-ROM.

CUSTÓDIO, C. C. Efeito do ácido sulfúrico concentrado sobre o potencial fisiológico de sementes de Brachiaria brizantha (A. Rich) Sapf cv. 'Marandu' e Brachiaria humidicola (Rendle) Schweick. cv. 'Tully' durante o armazenamento. 2000. 203 f. Tese (Doutorado em Ciências Biológicas)-Universidade Estadual Paulista, Rio Claro, 2000.

DIAS, M. C. L. L.; ALVES, S. J. Teste de tetrazólio em sementes de Panicum maximum e Brachiaria brizantha. Londrina: IAPar, 2000.

DIAS-FILHO, M. B.; CARVALHO, C. J. R. Physiological and morphological responses of Brachiaria spp. to flooding. Pesquisa Agropecuária Brasileira, Brasília, DF, v. 35, n. 10, p. 1959-1966, 2000.

EIRA, M. T. S. Comparação de métodos de quebra de dormência em sementes de capim andropogon. Revista Brasileira de Sementes, Brasília, DF, v. 5, n. 3, p. 37-49, 1983.

GONZALEZ, Y.; MENDOZA, F.; TORRES, R. Efecto del almacenamiento y la variación de temperatura sobre las semillas de Brachiaria decumbens cv. 'Basilisk'. Pastos y Forrajes, Matanzas, v. 16, n. 2, p. 155-165, 1993.

GROF, B. Viability of seeds of Brachiaria decumbens. Queensland Journal of Agricultural \& Animal Sciences, Queensland, v. 25, n. 3, p. 149-152, 1968.

LAPOINTE, S. L.; MILES, J. W. Germplasm case study: Brachiaria species. In: CIAT. Pastures for the tropical lowlands. Cali: CIAT, 1992. p. 43-55.

LIMA, V. L.; CARDOSO, V. J. M. On the germination and dormancy of dispersal units of Brachiaria decumbens Stapf. Arquivos de Biologia e Tecnologia, Curitiba, v. 39, n. 3, p. 595-606, 1996.

MACEDO, E. C.; GROTH, D.; LAGO, A. A. Efeito de escarificação com ácido sulfúrico na germinação de sementes de Brachiaria humidicola (Rendle) Schweick. Pesquisa Agropecuária Brasileira, Brasília, DF, v. 29, n. 3, p. 455-460, 1994.

OLIVEIRA, P. R. P.; MASTROCOLA, M. A. Brachiaria humidicola (Rendle) Schweickerdt: viabilidade de suas sementes. Boletim de Indústria Animal, Nova Odessa, v. 40, n. 1, p. 49-53, 1983.

PREVIERO, C. A. Efeito de métodos de preparo, graus de umidade, tratamento químico e tipos de embalagens no comportamento de sementes de Brachiaria brizantha (Hochst. ex A. Rich.) Stapf cv. Marandu. 1996. 92 f. Dissertação (Mestrado em Engenharia Agrícola)Faculdade de Engenharia Agrícola, Universidade Estadual de Campinas, Campinas, 1996.

RAO, I. M.; KERRIDGE, P. C.; MACEDO, M. C. M. Nutritional requirements of Brachiaria and adaptation to acid soils. In: MILES, J. W.; MAASS, B. L.; VALLE, C. B. Brachiaria: biology, agronomy, and improvement. 
Cali: CIAT; Campo Grande: Embrapa Gado de Corte, 1996. p. 53-71.

RIVERO, L.; ESPINOSA, J. Duración de la latencia en semillas de Brachiaria decumbens. Pasturas Tropicales, Cali, v. 10, n. 1, p. 20-23, 1988.

RODRIGUES, J. D. et al. Efeitos de diferentes métodos para a quebra da dormência em sementes de Brachiaria humidicola (Rendle) Schweickerdt. Científica, São Paulo, v. 14, n. 1/2, p. 65-72, 1986.
USBERTI, R.; MARTINS, L. Sulphuric acid scarification effects on Brachiaria brizantha, B. humidicola and Panicum maximum seed dormancy release. Revista Brasileira de Sementes, Pelotas, v. 29, n. 2, p. 143-147, 2007.

USBERTI, R.; USBERTI JR., J. A.; PATERNIANI, R. $\mathrm{S}$. Flowering cycle-related seed quality characteristics of 15 guinea grass (Panicum maximum Jacq.) hybrids. Seed Science \& Technology, Zürich, v. 28, n. 2, p. 437-443, 2000. 